\title{
Posterior Wall of the Hypopharynx
}

National Cancer Institute

\section{Source}

National Cancer Institute. Posterior Wall of the Hypopharynx. NCI Thesaurus. Code

C12249.

The region of the hypopharynx demarcated by a plane drawn at the level of the tip of the epiglottis to a plane at the inferior border of the cricoid. 